\title{
Comparative genomic and phylogenomic analyses of the Bifidobacteriaceae family
}

\author{
Gabriele Andrea Lugli', Christian Milani ${ }^{1}$, Francesca Turroni ${ }^{1}$, Sabrina Duranti ${ }^{1}$, Leonardo Mancabelli', \\ Marta Mangifesta ${ }^{2}$, Chiara Ferrario ${ }^{1}$, Monica Modesto ${ }^{3}$, Paola Mattarelli ${ }^{3}$, Killer Jirir ${ }^{4,5}$, Douwe van Sinderen ${ }^{6}$ \\ and Marco Ventura ${ }^{1 *}$
}

\begin{abstract}
Background: Members of the Bifidobacteriaceae family represent both dominant microbial groups that colonize the gut of various animals, especially during the suckling stage of their life, while they also occur as pathogenic bacteria of the urogenital tract. The pan-genome of the genus Bifidobacterium has been explored in detail in recent years, though genomics of the Bifidobacteriaceae family has not yet received much attention. Here, a comparative genomic analyses of 67 Bifidobacteriaceae (sub) species including all currently recognized genera of this family, i.e., Aeriscardovia, Alloscardovia, Bifidobacterium, Bombiscardovia, Gardnerella, Neoscardovia, Parascardovia, Pseudoscardovia and Scardovia, was performed. Furthermore, in order to include a representative of each of the 67 (currently recognized) (sub) species belonging to the Bifidobacteriaceae family, we sequenced the genomes of an additional 11 species from this family, accomplishing the most extensive comparative genomic analysis performed within this family so far.
\end{abstract}

Results: Phylogenomics-based analyses revealed the deduced evolutionary pathway followed by each member of the Bifidobacteriaceae family, highlighting Aeriscardovia aeriphila LMG 21773 as the deepest branch in the evolutionary tree of this family. Furthermore, functional analyses based on genome content unveil connections between a given member of the family, its carbohydrate utilization abilities and its corresponding host. In this context, bifidobacterial (sub) species isolated from humans and monkeys possess the highest relative number of acquired glycosyl hydrolase-encoding genes, probably in order to enhance their metabolic ability to utilize different carbon sources consumed by the host.

Conclusions: Within the Bifidobacteriaceae family, genomics of the genus Bifidobacterium has been extensively investigated. In contrast, very little is known about the genomics of members of the other eight genera of this family. In this study, we decoded the genome sequences of each member of the Bifidobacteriaceae family. Thanks to subsequent comparative genomic and phylogenetic analyses, the deduced pan-genome of this family, as well as the predicted evolutionary development of each taxon belonging to this family was assessed.

Keywords: Bifidobacteriaceae, Genomics, Phylogenomics, Bifidobacterium, Bifidobacteria

\footnotetext{
* Correspondence: marco.ventura@unipr.it

'Laboratory of Probiogenomics, Department of Chemistry, Life Sciences and

Environmental Sustainability, University of Parma, Parma, Italy

Full list of author information is available at the end of the article
}

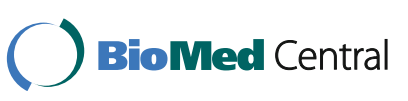

(c) The Author(s). 2017 Open Access This article is distributed under the terms of the Creative Commons Attribution 4.0 International License (http://creativecommons.org/licenses/by/4.0/), which permits unrestricted use, distribution, and reproduction in any medium, provided you give appropriate credit to the original author(s) and the source, provide a link to the Creative Commons license, and indicate if changes were made. The Creative Commons Public Domain Dedication waiver (http://creativecommons.org/publicdomain/zero/1.0/) applies to the data made available in this article, unless otherwise stated. 


\section{Background}

The Bifidobacteriaceae is the sole family member of the Bifidobacteriales order, and has been shown to represent the deepest branch within the Actinobacteria phylum [1]. Currently, the Bifidobacteriaceae family includes 55 (sub) species of the genus Bifidobacterium [1,2] and members of eight additional genera, i.e., Aeriscardovia, Alloscardovia, Bombiscardovia, Gardnerella, Neoscardovia, Parascardovia, Pseudoscardovia and Scardovia, which together encompass 12 species [1, 3]. Furthermore, a novel, yet unculturable species was identified from termites and included in the Bifidobacteriaceae family with the taxonomic denomination of 'Candidatus Ancillula trichonymphae' [4]. The name of this latter organism originates from a variety of flagellates of the genus Trichonympha, of which this strain is symbiont [4].

Bifidobacteriaceae are chemoorganotrophs with a fermentative type of metabolism, Gram-positive, nonspore-forming, non-motile, and anaerobic or facultative anaerobic bacteria [5]. They reside in different ecological niches, such as the human and animal gastrointestinal tract (GIT), oral cavity and the (social) insect gut [6], while they may also be found in blood and sewage, possibly due to environmental contamination. Many bifidobacteria are appreciated for their purported healthpromoting activities as well as their relevance in early life colonization and contributions to the infant gut glycobiome [7]. Conversely, members of the other genera of the Bifidobacteriaceae family are generally associated with human and animal dental caries, and are commonly isolated from human clinical samples of tonsil abscesses and bacterial vaginosis $[8,9]$. Furthermore, in contrast to bifidobacteria, which mainly include strict anaerobes with some exceptions, such as Bifidobacterium animalis subsp. lactis and Bifidobacterium asteroides [10, 11], other members of the family can grow under aerobic conditions and possess DNA with a lower $\mathrm{G}+\mathrm{C}$ content [12-14].

The most controversial species belonging to this family is Gardnerella vaginalis [9], originally described by Leopold in 1953 and named Haemophilus vaginalis [15]. Subsequently, taxonomic studies mixed with data obtained from biochemical analyses and electron microscopic examinations, supported the need for its re-classification as a new genus [16, 17]. Currently, G. vaginalis is described as an opportunistic pathogen whose presence is tightly associated with bacterial vaginosis $[18,19]$. Furthermore, Parascardovia denticolens and Scardovia inopinata, which were classified in 1996 as Bifidobacterium denticolens and Bifidobacterium inopinatum [20], respectively, together with Scardovia wiggsiae and Bifidobacterium dentium are associated with human dental caries [21]. While members of these species are present at high numbers in the saliva of adults, their presence strongly correlates with other caries-associated organisms [22, 23].
Notably, comparative genome analyses of the genus Bifidobacterium have been targeting the entire genus [2, 24] or one specific bifidobacterial taxa, i.e., B. bifidum [25], B. adolescentis [26], B. breve [27], B. longum [28] or the $B$. animalis subsp. lactis taxon [11]. In contrast, the genomics of the other eight genera belonging to the Bifidobacteriaceae family have not yet been investigated in detail. Here, we decoded the genomes of 11 species belonging to the Bifidobacteriaceae family for which there was no prior genomic data. Furthermore, we performed an in depth comparative genomic analysis, as well as a phylogenetic reconstruction of the 67 (sub) species currently assigned to the Bifidobacteriaceae family.

\section{Methods}

\section{Bifidobacteriaceae strains}

We retrieved the complete and partial genome sequences of 56 Bifidobacteriaceae strains from the National Center for Biotechnology Information (NCBI) public database (Table 1). Additionally, we sequenced and analyzed the genome sequences of 11 Bifidobacteriaceae strains deposited in the GenBank sequence database (Table 2).

\section{Bacterial strains and growth condition}

Bifidobacteriaceae pure cultures were inoculated in de Man-Rogosa-Sharpe (MRS) medium (Scharlau Chemie) supplemented with $0.05 \%$ (wt/vol) L-cysteine hydrochloride and were grown in an anaerobic atmosphere (2.99\% $\mathrm{H}_{2}, 17.01 \% \mathrm{CO}_{2}$, and $80 \% \mathrm{~N}_{2}$ ) in a chamber (Concept 400, Ruskin) at $37{ }^{\circ} \mathrm{C}$ for $16 \mathrm{~h}$. DNA was extracted as described previously [29] and subjected to further phenol-chloroform purification using a previously described protocol [30].

\section{Genome sequencing and assemblies}

DNA extracted from the various Bifidobacteriaceae strains was subjected to whole genome sequencing using MiSeq (Illumina, UK) at GenProbio srl (Parma, Italy) following the supplier's protocol (Illumina, UK). Fastq files of the paired-end reads obtained from targeted genome sequencing of the isolated strains were used as input for genome assemblies through the MEGAnnotator pipeline [31]. The MIRA program (version 4.0.2) was used for de novo assembly of each Bifidobacteriaceae genome sequence [32].

\section{Sequence annotation}

Protein-encoding open reading frames (ORFs) were predicted using Prodigal [33]. Transfer RNA genes were identified using tRNAscan-SE v1.4 [34], while ribosomal RNA genes were detected using RNAmmer v1.2 [35]. Results of the gene-finder program were combined with data from RAPSearch2 analysis (Reduced Alphabet based Protein similarity Search) [36] of a non-redundant protein database 
Table 1 General features of Bifidobacteriaceae genomes

\begin{tabular}{|c|c|c|c|c|c|c|c|c|c|c|c|}
\hline $\begin{array}{l}\text { Taxon } \\
\text { number }\end{array}$ & $\begin{array}{l}\text { Bifidobacteriaceae } \\
\text { strains }\end{array}$ & $\begin{array}{l}\text { Genome } \\
\text { status }^{\mathrm{a}}\end{array}$ & $\begin{array}{l}\text { Genome } \\
\text { size }\end{array}$ & $\begin{array}{l}\text { GC } \\
\text { content }\end{array}$ & $\begin{array}{l}\text { ORFs } \\
\text { number }\end{array}$ & $\begin{array}{l}\text { rRNA } \\
\text { loci }\end{array}$ & $\begin{array}{l}\text { tRNA } \\
\text { number }\end{array}$ & $\begin{array}{l}\text { GHs } \\
\text { number }\end{array}$ & $\begin{array}{l}\text { GH } \\
\text { index }\end{array}$ & Isolation & $\begin{array}{l}\text { Accession } \\
\text { number }\end{array}$ \\
\hline 01 & $\begin{array}{l}\text { B. actinocoloniiforme } \\
\text { DSM } 22766\end{array}$ & Draft (4) & $1,823,388$ & 62.71 & 1484 & 2 & 46 & 41 & 0.0276 & $\begin{array}{l}\text { Bumblebee } \\
\text { digestive tract }\end{array}$ & JGYK00000000 \\
\hline 02 & $\begin{array}{l}\text { B. adolescentis ATCC } \\
15703\end{array}$ & Complete & $2,089,645$ & 59.18 & 1649 & 5 & 54 & 81 & 0.0491 & $\begin{array}{l}\text { Intestine of } \\
\text { adult }\end{array}$ & AP009256.1 \\
\hline 03 & $\begin{array}{l}\text { B. aesculapii DSM } \\
26737\end{array}$ & $\begin{array}{l}\text { Draft } \\
(118)\end{array}$ & $2,794,396$ & 64.58 & 2172 & 6 & 60 & 82 & 0.0378 & $\begin{array}{l}\text { Faeces of } \\
\text { baby common } \\
\text { marmosets }\end{array}$ & BCFK00000000 \\
\hline 04 & $\begin{array}{l}\text { B. angulatum LMG } \\
11039\end{array}$ & Draft (6) & $2,003,806$ & 59.41 & 1523 & 4 & 48 & 63 & 0.0414 & Human faeces & JGYL00000000 \\
\hline 05 & $\begin{array}{l}\text { B. animalis subsp. } \\
\text { animalis LMG } 10508\end{array}$ & Draft (13) & $1,915,007$ & 60.47 & 1527 & 3 & 52 & 48 & 0.0314 & Rat feces & JGYM00000000 \\
\hline 06 & $\begin{array}{l}\text { B. animalis subsp. } \\
\text { lactis DSM } 10140\end{array}$ & Complete & $1,938,606$ & 60.48 & 1518 & 4 & 52 & 53 & 0.0349 & Fermented milk & СР001606.1 \\
\hline 07 & B. aquikefiri LMG 28769 & Draft (18) & $2,408,364$ & 52.29 & 2000 & 2 & 45 & 56 & 0.0280 & $\begin{array}{l}\text { Household } \\
\text { water kefir }\end{array}$ & MWXA00000000 \\
\hline 08 & $\begin{array}{l}\text { B. asteroides LMG } 10735 \\
\text { (PRL2011) }\end{array}$ & Complete & $2,167,304$ & 60.05 & 1653 & 2 & 44 & 58 & 0.0351 & $\begin{array}{l}\text { Honeybee } \\
\text { hindgut }\end{array}$ & СР003325.1 \\
\hline 09 & B. biavatii DSM 23969 & Draft (56) & $3,252,147$ & 63.1 & 2557 & 5 & 61 & 137 & 0.0536 & $\begin{array}{l}\text { Feces of } \\
\text { tamarin }\end{array}$ & JGYN00000000 \\
\hline 10 & B. bifidum LMG 11041 & Draft (2) & $2,208,468$ & 62.67 & 1704 & 3 & 53 & 66 & 0.0387 & $\begin{array}{l}\text { Brest-feed } \\
\text { Infant feaces }\end{array}$ & JGYO00000000 \\
\hline 11 & $\begin{array}{l}\text { B. bohemicum DSM } \\
22767\end{array}$ & Draft (5) & $2,052,470$ & 57.45 & 1632 & 2 & 47 & 56 & 0.0343 & $\begin{array}{l}\text { Bumblebee } \\
\text { digestive tract }\end{array}$ & JGYP00000000 \\
\hline 12 & B. bombi DSM 19703 & Draft (4) & $1,895,239$ & 56.08 & 1454 & 2 & 48 & 44 & 0.0303 & $\begin{array}{l}\text { Bumblebee } \\
\text { digestive tract }\end{array}$ & ATLK00000000 \\
\hline 13 & B. boum LMG 10736 & Draft (18) & $2,171,356$ & 59.31 & 1726 & 4 & 49 & 45 & 0.0261 & Bovine rumen & JGYQ00000000 \\
\hline 14 & B. breve LMG 13208 & Draft (31) & $2,263,780$ & 58.88 & 1887 & 2 & 53 & 67 & 0.0355 & Infant intestine & JGYR00000000 \\
\hline 15 & $\begin{array}{l}\text { B. callitrichos DSM } \\
23973\end{array}$ & Draft (33) & $2,887,313$ & 63.52 & 2364 & 3 & 58 & 105 & 0.0444 & $\begin{array}{l}\text { Feces of } \\
\text { common } \\
\text { marmoset }\end{array}$ & JGYS00000000 \\
\hline 16 & $\begin{array}{l}\text { B. catenulatum LMG } \\
11043\end{array}$ & Draft (11) & $2,082,756$ & 56.11 & 1664 & 5 & 55 & 91 & 0.0547 & Adult intestine & JGYT00000000 \\
\hline 17 & $\begin{array}{l}\text { B. choerinum LMG } \\
10510\end{array}$ & Draft (20) & $2,096,123$ & 65.53 & 1672 & 3 & 55 & 54 & 0.0323 & Piglet faeces & JGYU00000000 \\
\hline 18 & B. commune R-52791 & Dreaft (4) & $1,633,662$ & 53.93 & 1303 & 1 & 47 & 31 & 0.0238 & $\begin{array}{l}\text { Bumble bee } \\
\text { gut }\end{array}$ & FMBL00000000 \\
\hline 19 & $\begin{array}{l}\text { B. coryneforme LMG } \\
18911\end{array}$ & Complete & $1,755,151$ & 60.51 & 1364 & 3 & 56 & 43 & 0.0315 & $\begin{array}{l}\text { Honeybee } \\
\text { hindgut }\end{array}$ & CP007287 \\
\hline 20 & $\begin{array}{l}\text { B. crudilactis LMG } \\
23609\end{array}$ & Draft (6) & $2,362,816$ & 57.72 & 1883 & 2 & 45 & 51 & 0.0271 & Raw cow milk & JHAL00000000 \\
\hline 21 & B. cuniculi LMG 10738 & Draft (41) & $2,531,592$ & 64.87 & 2194 & 4 & 63 & 70 & 0.0319 & Rabbit faeces & JGY00000000 \\
\hline 22 & $\begin{array}{l}\text { B. dentium LMG } \\
11045(\mathrm{Bd} 1)\end{array}$ & Complete & $2,636,367$ & 58.54 & 2129 & 4 & 55 & 113 & 0.0531 & Oral cavity & СР001750.1 \\
\hline 23 & $\begin{array}{l}\text { B. eulemuris DSM } \\
100216\end{array}$ & Draft (34) & $2,913,389$ & 62.2 & 2331 & 2 & 53 & 126 & 0.0541 & $\begin{array}{l}\text { Faeces of the } \\
\text { black lemur }\end{array}$ & MWWZ00000000 \\
\hline 24 & $\begin{array}{l}\text { B. gallicum LMG } \\
11596\end{array}$ & Draft (12) & $2,004,594$ & 57.61 & 1507 & 2 & 58 & 45 & 0.0299 & Adult intestine & JGYW00000000 \\
\hline 25 & $\begin{array}{l}\text { B. gallinarum LMG } \\
11586\end{array}$ & Draft (10) & $2,160,836$ & 64.22 & 1654 & 2 & 53 & 78 & 0.0472 & $\begin{array}{l}\text { Chicken } \\
\text { caecum }\end{array}$ & JGYX00000000 \\
\hline 26 & B. hapali DSM 100202 & Draft (76) & $2,834,308$ & 54.5 & 2253 & 3 & 54 & 121 & 0.0537 & $\begin{array}{l}\text { Faeces of } \\
\text { baby common } \\
\text { marmosets }\end{array}$ & MWWY00000000 \\
\hline 27 & B. indicum LMG 11587 & Complete & $1,734,546$ & 60.49 & 1352 & 3 & 47 & 41 & 0.0303 & Insect & СР006018 \\
\hline
\end{tabular}


Table 1 General features of Bifidobacteriaceae genomes (Continued)

\begin{tabular}{|c|c|c|c|c|c|c|c|c|c|c|c|}
\hline 28 & $\begin{array}{l}\text { B. kashiwanohense } \\
\text { DSM } 21854\end{array}$ & Draft (30) & $2,307,960$ & 56.2 & 1948 & 5 & 53 & 91 & 0.0467 & Infant feaces & JGYY00000000 \\
\hline 29 & B. lemurum DSM 28807 & Draft (38) & $2,944,293$ & 62.64 & 2321 & 3 & 49 & 122 & 0.0526 & $\begin{array}{l}\text { Faeces of the } \\
\text { ring-tailed lemur }\end{array}$ & MWWX00000000 \\
\hline 30 & $\begin{array}{l}\text { B. longum subsp. } \\
\text { infantis ATCC } 15697\end{array}$ & Complete & $2,832,748$ & 59.86 & 2500 & 4 & 79 & 71 & 0.0284 & Intestine of infant & AP010889.1 \\
\hline 31 & $\begin{array}{l}\text { B. longum subsp. } \\
\text { longum LMG } 13197\end{array}$ & Draft (8) & $2,384,703$ & 60.33 & 1899 & 3 & 71 & 73 & 0.0384 & Adult intestine & JGYZ00000000 \\
\hline 32 & $\begin{array}{l}\text { B. longum subsp. suis } \\
\text { LMG } 21814\end{array}$ & Draft (36) & $2,335,832$ & 59.96 & 1955 & 3 & 55 & 74 & 0.0379 & Pig faeces & JGZA00000000 \\
\hline 33 & B. magnum LMG 11591 & Draft (13) & $1,822,476$ & 58.72 & 1507 & 5 & 56 & 46 & 0.0305 & Rabbit faeces & JGZB00000000 \\
\hline 34 & $\begin{array}{l}\text { B. merycicum LMG } \\
11341\end{array}$ & Draft (16) & $2,280,236$ & 60.33 & 1741 & 3 & 53 & 66 & 0.0379 & Bovine rumen & JGZC00000000 \\
\hline 35 & B. minimum LMG 11592 & Draft (18) & $1,892,860$ & 62.73 & 1590 & 2 & 53 & 41 & 0.0258 & Sewage & JGZD00000000 \\
\hline 36 & $\begin{array}{l}\text { B. mongoliense } \\
\text { DSM } 21395\end{array}$ & Draft (43) & $2,170,490$ & 62.78 & 1798 & 2 & 47 & 65 & 0.0362 & $\begin{array}{l}\text { Fermented } \\
\text { mare's milk }\end{array}$ & JGZE00000000 \\
\hline 37 & $\begin{array}{l}\text { B. moukalabense } \\
\text { DSM } 27321\end{array}$ & Draft (12) & $2,515,335$ & 59.87 & 2046 & 4 & 56 & 105 & 0.0513 & $\begin{array}{l}\text { Feces of wild } \\
\text { western lowland } \\
\text { gorilla }\end{array}$ & AZMV00000000 \\
\hline 38 & $\begin{array}{l}\text { B. myosotis DSM } \\
100196\end{array}$ & Draft (58) & $2,944,195$ & 62.55 & 2168 & 4 & 56 & 101 & 0.0466 & $\begin{array}{l}\text { Faeces of } \\
\text { baby common } \\
\text { marmosets }\end{array}$ & MWWW00000000 \\
\hline 39 & $\begin{array}{l}\text { B. pseudocatenulatum } \\
\text { LMG } 10505\end{array}$ & Draft (10) & $2,283,767$ & 56.36 & 1771 & 6 & 53 & 85 & 0.0480 & Infant faeces & JGZF00000000 \\
\hline 40 & $\begin{array}{l}\text { B. pseudolongum subsp. } \\
\text { globosum LMG } 11569\end{array}$ & Draft (26) & $1,935,255$ & 63.39 & 1574 & 4 & 52 & 53 & 0.0337 & Bovine rumen & JGZG00000000 \\
\hline 41 & $\begin{array}{l}\text { B. pseudolongum subsp. } \\
\text { pseudolongum LMG } \\
11571\end{array}$ & Draft (11) & $1,898,684$ & 63.06 & 1495 & 3 & 52 & 57 & 0.0381 & Swine faeces & JGZH00000000 \\
\hline 42 & $\begin{array}{l}\text { B. psychraerophilum } \\
\text { LMG } 21775\end{array}$ & Draft (11) & $2,615,078$ & 58.75 & 2122 & 1 & 45 & 80 & 0.0377 & Pig caecum & JGZI00000000 \\
\hline 43 & $\begin{array}{l}\text { B. pullorum DSM } \\
20433\end{array}$ & Draft (38) & $2,100,948$ & 64.31 & 1678 & 2 & 51 & 81 & 0.0479 & Faeces of chicken & JDUI00000000 \\
\hline 44 & B. reuteri DSM 23975 & Draft (28) & $2,847,572$ & 60.45 & 2149 & 4 & 53 & 85 & 0.0396 & $\begin{array}{l}\text { Feces of } \\
\text { common } \\
\text { marmoset }\end{array}$ & JGZK00000000 \\
\hline 45 & $\begin{array}{l}\text { B. ruminantium LMG } \\
21811\end{array}$ & Draft (23) & $2,249,807$ & 59.18 & 1832 & 4 & 50 & 62 & 0.0338 & Bovine rumen & JGZL00000000 \\
\hline 46 & B. saeculare LMG 14934 & Draft (14) & $2,263,283$ & 63.75 & 1857 & 2 & 48 & 82 & 0.0442 & Rabbit faeces & JGZM00000000 \\
\hline 47 & B. saguini DSM 23967 & Draft (33) & $2,787,036$ & 56.35 & 2321 & 5 & 59 & 104 & 0.0448 & Feces of tamarin & JGZN00000000 \\
\hline 48 & B. scardovii LMG 21589 & Draft (34) & $3,141,793$ & 64.63 & 2480 & 3 & 55 & 128 & 0.0516 & Blood & JGZO00000000 \\
\hline 49 & $\begin{array}{l}\text { B. stellenboschense } \\
\text { DSM } 23968\end{array}$ & Draft (40) & $2,812,864$ & 65.34 & 2202 & 6 & 59 & 80 & 0.0363 & Feces of tamarin & JGZP00000000 \\
\hline 50 & B. subtile LMG 11597 & Draft (27) & $2,790,088$ & 60.92 & 2260 & 1 & 47 & 56 & 0.0248 & Sewage & JGZR00000000 \\
\hline 51 & $\begin{array}{l}\text { B. thermacidophilum } \\
\text { subsp. porcinum LMG } \\
21689\end{array}$ & Draft (3) & $2,079,368$ & 60.2 & 1738 & 3 & 40 & 46 & 0.0265 & Piglet faeces & JGZS00000000 \\
\hline 52 & $\begin{array}{l}\text { B. thermacidophilum } \\
\text { subsp. thermacidophilum } \\
\text { LMG } 21395\end{array}$ & Draft (8) & $2,233,072$ & 60.38 & 1823 & 4 & 48 & 47 & 0.0258 & $\begin{array}{l}\text { Anaerobic } \\
\text { digester }\end{array}$ & JGZT00000000 \\
\hline 53 & $\begin{array}{l}\text { B. thermophilum } \\
\text { DSM } 20212\end{array}$ & Draft (50) & $2,252,351$ & 60.07 & 1756 & 3 & 49 & 58 & 0.0341 & Bovine rumen & JHWM00000000 \\
\hline 54 & B. tissieri DSM 100201 & Draft (38) & $2,873,483$ & 61.05 & 2260 & 2 & 60 & 79 & 0.0350 & $\begin{array}{l}\text { Faeces of } \\
\text { baby common } \\
\text { marmosets }\end{array}$ & MWWV00000000 \\
\hline
\end{tabular}


Table 1 General features of Bifidobacteriaceae genomes (Continued)

\begin{tabular}{|c|c|c|c|c|c|c|c|c|c|c|c|}
\hline 55 & $\begin{array}{l}\text { B. tsurumiense JCM } \\
13495\end{array}$ & Draft (25) & $2,164,426$ & 52.84 & 1629 & 3 & 46 & 85 & 0.0522 & $\begin{array}{l}\text { Hamster dental } \\
\text { plaque }\end{array}$ & JGZU00000000 \\
\hline 56 & $\begin{array}{l}\text { Aeriscardovia aeriphila } \\
\text { LMG } 21773\end{array}$ & Draft (12) & $1,631,097$ & 54.03 & 1288 & 3 & 47 & 53 & 0.0411 & Pig caecum & MWWU00000000 \\
\hline 57 & $\begin{array}{l}\text { Alloscardovia criceti } \\
\text { DSM } 17774\end{array}$ & Draft (11) & $1,884,654$ & 50.06 & 1524 & 4 & 45 & 58 & 0.0381 & $\begin{array}{l}\text { Dental plaque, } \\
\text { golden hamster }\end{array}$ & AQXR00000000 \\
\hline 58 & $\begin{array}{l}\text { Alloscardovia macacae } \\
\text { DSM } 24762\end{array}$ & Draft (20) & $1,891,581$ & 55.82 & 1552 & 4 & 48 & 50 & 0.0322 & $\begin{array}{l}\text { Milk of a female } \\
\text { macaque bred }\end{array}$ & MWWT00000000 \\
\hline 59 & $\begin{array}{l}\text { Alloscardovia omnicolens } \\
\text { DSM } 21503\end{array}$ & Draft (43) & $1,847,146$ & 46.65 & 1564 & 3 & 47 & 56 & 0.0358 & Human tonsil & ATVB00000000 \\
\hline 60 & $\begin{array}{l}\text { Bombiscardovia } \\
\text { coagulans DSM } 22924\end{array}$ & Draft (15) & $1,741,326$ & 47.33 & 1441 & 2 & 45 & 36 & 0.0250 & $\begin{array}{l}\text { Bumblebee } \\
\text { digestive tract }\end{array}$ & MWWS00000000 \\
\hline 61 & $\begin{array}{l}\text { Gardnerella vaginalis } \\
\text { ATCC } 14018\end{array}$ & Complete & $1,667,406$ & 41.36 & 1271 & 2 & 45 & 41 & 0.0323 & Vaginal secretions & AP012332 \\
\hline 62 & $\begin{array}{l}\text { Neoscardovia } \\
\text { arbecensis } 1879\end{array}$ & Draft (21) & $1,971,875$ & 54.25 & 1641 & 2 & 45 & 56 & 0.0341 & Feces of rabbit & n.d. \\
\hline 63 & $\begin{array}{l}\text { Parascardovia } \\
\text { denticolens DSM } 10105\end{array}$ & Complete & $1,890,857$ & 58.31 & 1528 & 2 & 45 & 56 & 0.0366 & $\begin{array}{l}\text { Human dental } \\
\text { caries }\end{array}$ & AP012333 \\
\hline 64 & $\begin{array}{l}\text { Pseudoscardovia radai } \\
\text { DSM } 24742\end{array}$ & Draft (35) & $2,436,770$ & 65.03 & 1779 & 3 & 47 & 41 & 0.0230 & $\begin{array}{l}\text { Digestive tract } \\
\text { of wild pig } \\
\text { Sus scrofa }\end{array}$ & MWWR00000000 \\
\hline 65 & $\begin{array}{l}\text { Pseudoscardovia suis } \\
\text { DSM } 24744\end{array}$ & Draft (26) & $2,270,618$ & 60.57 & 1736 & 3 & 48 & 45 & 0.0259 & $\begin{array}{l}\text { Digestive tract } \\
\text { of wild pig } \\
\text { Sus scrofa }\end{array}$ & MWWQ00000000 \\
\hline 66 & $\begin{array}{l}\text { Scardovia inopinata } \\
\text { JCM } 12537\end{array}$ & Complete & $1,797,862$ & 48.63 & 1465 & 2 & 46 & 49 & 0.0334 & $\begin{array}{l}\text { Human dental } \\
\text { caries }\end{array}$ & AP012334 \\
\hline 67 & $\begin{array}{l}\text { Scardovia wiggsiae } \\
\text { F0424 }\end{array}$ & Complete & $1,550,817$ & 52.93 & 1244 & 2 & 45 & 32 & 0.0257 & $\begin{array}{l}\text { Human dental } \\
\text { caries }\end{array}$ & AKCI00000000 \\
\hline
\end{tabular}

${ }^{a}$ Numbers in brackets indicate the numbers of assembled contigs

Table 2 Sequencing data of the Bifidobacteriaceae genomes

\begin{tabular}{|c|c|c|c|c|c|c|c|c|c|}
\hline Bifidobacteriaceae Strains & $\begin{array}{l}\text { Genome } \\
\text { status }^{\mathrm{a}}\end{array}$ & $\begin{array}{l}\text { Sequence } \\
\text { coverage }\end{array}$ & $\begin{array}{l}\text { Genome } \\
\text { size }\end{array}$ & $\begin{array}{l}\text { GC } \\
\text { content }\end{array}$ & $\begin{array}{l}\text { ORFs } \\
\text { number }\end{array}$ & $\begin{array}{l}\text { rRNA } \\
\text { loci }\end{array}$ & $\begin{array}{l}\text { tRNA } \\
\text { number }\end{array}$ & Isolation & Accession number \\
\hline Aeriscardovia aeriphila LMG 21773 & Draft (12) & 259.66 & $1,631,097$ & 54.03 & 1288 & 3 & 47 & Pig caecum & MWWU00000000 \\
\hline Alloscardovia macacae DSM 24762 & Draft (20) & 173.37 & $1,891,581$ & 55.82 & 1552 & 4 & 48 & $\begin{array}{l}\text { Milk of a female } \\
\text { macaque bred }\end{array}$ & MWWT00000000 \\
\hline $\begin{array}{l}\text { Bifidobacterium aquikefiri } \\
\text { LMG } 28769\end{array}$ & Draft (18) & 96.25 & $2,408,364$ & 52.29 & 2000 & 2 & 45 & $\begin{array}{l}\text { Household water } \\
\text { kefir }\end{array}$ & MWXA00000000 \\
\hline $\begin{array}{l}\text { Bifidobacterium eulemuris } \\
\text { DSM } 100216\end{array}$ & Draft (34) & 75.23 & $2,913,389$ & 62.2 & 2331 & 2 & 53 & $\begin{array}{l}\text { Faeces of the black } \\
\text { lemur }\end{array}$ & MWWZ00000000 \\
\hline $\begin{array}{l}\text { Bifidobacterium hapali } \\
\text { DSM } 100202\end{array}$ & Draft (76) & 109.83 & $2,834,308$ & 54.5 & 2253 & 3 & 54 & $\begin{array}{l}\text { Faeces of baby } \\
\text { common marmosets }\end{array}$ & MWWY00000000 \\
\hline $\begin{array}{l}\text { Bifidobacterium lemurum } \\
\text { DSM } 28807\end{array}$ & Draft (38) & 71.87 & $2,944,293$ & 62.64 & 2321 & 3 & 49 & $\begin{array}{l}\text { Faeces of the } \\
\text { ring-tailed lemur }\end{array}$ & MWWX00000000 \\
\hline $\begin{array}{l}\text { Bifidobacterium myosotis } \\
\text { DSM } 100196\end{array}$ & Draft (58) & 57.03 & $2,944,195$ & 62.55 & 2168 & 4 & 56 & $\begin{array}{l}\text { Faeces of baby } \\
\text { common marmosets }\end{array}$ & MWWW00000000 \\
\hline $\begin{array}{l}\text { Bifidobacterium tissieri } \\
\text { DSM } 100201\end{array}$ & Draft (38) & 66.77 & $2,873,483$ & 61.05 & 2260 & 2 & 60 & $\begin{array}{l}\text { Faeces of baby } \\
\text { common marmosets }\end{array}$ & MWWV00000000 \\
\hline $\begin{array}{l}\text { Bombiscardovia coagulans } \\
\text { DSM } 22924\end{array}$ & Draft (15) & 220.35 & $1,741,326$ & 47.33 & 1441 & 2 & 45 & $\begin{array}{l}\text { Bumblebee digestive } \\
\text { tract }\end{array}$ & MWWS00000000 \\
\hline Pseudoscardovia radai DSM 24742 & Draft (35) & 145.91 & $2,436,770$ & 65.03 & 1779 & 3 & 47 & $\begin{array}{l}\text { Digestive tract of } \\
\text { wild pig Sus scrofa }\end{array}$ & MWWR00000000 \\
\hline Pseudoscardovia suis DSM 24744 & Draft (26) & 140.27 & $2,270,618$ & 60.57 & 1736 & 3 & 48 & $\begin{array}{l}\text { Digestive tract of } \\
\text { wild pig Sus scrofa }\end{array}$ & MWWQ00000000 \\
\hline
\end{tabular}


provided by the National Center for Biotechnology Information (NCBI) and Hidden Markov Model profile (HMM) search (http://hmmer.org/) in the manually curated PfamA protein family database [37]. The combined results were inspected by Artemis [38], which was used for manual editing purposes aimed at verifying and, where necessary, redefining the start of each predicted coding region, and to remove or add coding regions.

\section{Bifidobacteriaceae pan-genome analysis}

For the 67 genome sequences of each member of the Bifidobacteriaceae family, a pan-genome calculation was performed using the PGAP pipeline [39]. The ORF contents from all genomes used in this study were organized in functional clusters using the GF (Gene Family) method involving comparison of each protein to all other proteins using BLAST analysis (cutoff E-value of $1 \times 10^{-5}$ and 50\% identity over at least $50 \%$ of both protein sequences), followed by clustering into protein families, named Bifidobacteriaceae-specific clusters of orthologous groups (BaeCOGs), using MCL (graph-theory-based Markov clustering algorithm) [40]. A pan-genome profile was built using an optimized algorithm incorporated in PGAP software, based on a presence/absence matrix that included all identified BaeCOGs in the analyzed genomes. Following this, unique protein families for each of the 67 Bifidobacteriaceae genomes were classified. Protein families shared between all genomes, named core BaeCOGs, were defined by selecting the families that contained at least one protein member for each genome.

\section{Phylogenetic comparison}

The concatenated core genome sequence of the family (core BaeCOGs), was aligned using MAFFT [41], and phylogenetic trees were constructed using the neighborjoining method in Clustal W, version 2.1 [42]. The core genome supertree was built using FigTree (http://tree. bio.ed.ac.uk/software/figtree/). Values of average nucleotide identity (ANI) were calculated using the program JSpecies, version 1.2.1 [43].

\section{Functional analysis}

The prediction of genes encoding enzymes that possess structurally-related catalytic and carbohydrate-binding modules catalyzing hydrolysis, modification or synthesis of glycoside bounds was performed by means of the CAZy database [44]. Functional annotation of each gene was performed employing the eggNOG database [45]. A survey of complete pathways involved in both primary and secondary metabolism was performed by means of the MetaCyc metabolic pathways database [46]. Gene function was predicted using a cutoff E-value of $1 \times 10^{-10}$ to identify the best hit from each database.

\section{Gene gain/loss through evolution reconstruction}

Predicting gene acquisition or gene loss as a result of evolution of the bacterial species with at least four available genomes was performed with Count software [47] using Dollo's parsimony.

\section{Results and discussion}

\section{General genome features of Bifidobacteriaceae genomes}

Genome sequences of six bifidobacterial species, i.e., Bifidobacterium aquikefiri LMG 28769, Bifidobacterium eulemuris DSM 100216, Bifidobacterium hapali DSM 100202, Bifidobacterium lemurum DSM 28807, Bifidobacterium myosotis DSM 100196 and Bifidobacterium tissieri DSM 100201, as well as five chromosomes belonging to different genera of the Bifidobacteriaceae family, including Aeriscardovia aeriphila LMG 21773, Alloscardovia macacae DSM 24762, Bombiscardovia coagulans DSM 22924 and Pseudoscardovia radai DSM 24742 and Pseudoscardovia suis DSM 24744, were decoded through shotgun sequencing. Genome features and sequencing data of these 11 Bifidobacteriaceae genomes are summarized in Table 2. In order to provide a complete genome analysis of the Bifidobacteriaceae family, a representative genome sequence for each of the currently described 67 (sub) species belonging to this family, was retrieved from the NCBI public database (Table 1). Due to the incomplete genome sequences of Candidatus Ancillula trichonymphae ImTpAt recovered from the NCBI database, and the impossibility to retrieve this strain from any public bacterial culture collection, we decided to exclude the genome sequences of ImTpAt from our analyses. The combination of genomic data of 56 previously characterized bifidobacterial taxa $[2,3,48-51]$ with the chromosome sequences of the 11 Bifidobacteriaceae species reported here, resulted in the most comprehensive database of genome sequences of representative members of the Bifidobacteriaceae family. The Bifidobacteriaceae genomes have an average genome length of $2.25 \mathrm{Mb}$, and range in size from $1.55 \mathrm{Mb}$ for Scardovia wiggsiae F0424 to $3.25 \mathrm{Mb}$ for Bifidobacterium biavatii DSM 23969, corresponding to 1244 and 2557 predicted protein-encoding open reading frames (ORFs), respectively (Table 1). Average genomic GC content ranges from $41.36 \%$ for Gardnerella vaginalis ATCC 14018 to $65.53 \%$ for Bifidobacterium choerinum LMG 10510, and revealed a higher average for the bifidobacterial strains $(60.24 \%)$ as compared to the other taxa of the Bifidobacteriaceae genera (52.91\%) [52]. The average genome size of bifidobacterial strains is also higher than that observed for the other family members, being $2.33 \mathrm{Mb}$ and $1.88 \mathrm{Mb}$, respectively, highlighting a gene ratio of 1.24 (obtained by dividing the average gene number of bifidobacterial (sub) species with that of the non-bifidobacterial taxa of the Bifidobacteriaceae family) 
in favor of the bifidobacterial strains. The larger gene complement possessed by members of the Bifidobacterium genus may reflect an increased genetic variability of this genus, endowing bifidobacteria with an enhanced ability to adapt to a broad range of ecological niches as compared to other members of the Bifidobacteriaceae family, which, as is listed in Table 1, were isolated from a very limited number of environments. Further analyses involving mobile elements of the different species belonging to the Bifidobacteriaceae family reveal varying percentages of such mobile elements (calculated as a proportion of the total number of genes within these genomes), ranging from $0.07 \%$ for Bifidobacterium indicum LMG 11587 to $5.02 \%$ for B. hapali DSM 100202. Furthermore, the overall Bifidobacterium genus contains a percentage of $1.5 \%$ mobile elements, while nonbifidobacterial species reveal a percentage of $0.9 \%$, highlighting an approximate mobile element ratio of 2.1 (obtained by dividing the average contents of the predicted mobile elements of bifidobacterial (sub) species with that of the non-bifidobacterial taxa belonging to the Bifidobacteriaceae family). Thus, the larger abundance of predicted mobile elements in bifidobacterial genomes reflects the above mentioned increased genomic variability of these strains. Interestingly, the number of tRNA genes in bifidobacteria ranges from 40 for Bifidobacterium thermacidophilum subsp. porcinum LMG 21689 to 79 for Bifidobacterium longum subsp. infantis ATCC 15697, while in other members of the Bifidobacteriaceae the tRNA abundance seems to be much less variable, ranging from 45 to 48 (Table 1). Nevertheless, the Bifidobacteriaceae strains that do not belong to the Bifidobacterium genus possess at least one tRNA gene for each of the 20 amino acids (Additional file 1: Table S1). Additionally, a deeper screening of the anticodon sequences for each (sub) species does not display major differences, except for a lower abundance of the anticodon GGG in Proline tRNA of the Bifidobacteriaceae strains that do not belong to the Bifidobacterium genus (Additional file 1: Table S1). Consequently, it may be argued that the lower number of tRNA genes among certain members of the Bifidobacteriaceae family is not associated with a simplification of the codon usage of these strains. Furthermore, while the bifidobacterial genomes contain between one and six rRNA loci, with an average of 3.2 per genome [2], the genomes of the Aeriscardovia, Alloscardovia, Bombiscardovia, Gardnerella, Neoscardovia, Parascardovia, Pseudoscardovia and Scardovia genera exhibit a lower average number of rRNA loci, i.e., 2.6, which is consistent with the less extensive ORFome and tRNA arsenal identified in the corresponding genomes (Table 2).

Furthermore, in silico analyses of the 12 genomes of the Bifidobacteriaceae family based on the Virulence Factor Database (VFDB) [53], did not reveal the occurrence of any virulence genetic determinants. Such results confirm previously reported findings for the genome of $B$. dentium Bd1 [23].

\section{Pan-genome, core genome and unique genes of the Bifidobacteriaceae family}

Comparative genome analyses involving the 67 (sub) species belonging to the Bifidobacteriaceae family were performed to unveil the corresponding pan-genome, core genome and unique genes of this bacterial family. All genomes were subjected to identical ORFs finding and annotation protocols [31] in order to generate comparable data sets for each Bifidobacteriaceae taxa. A total of 25,744 BaeCOGs (Bifidobacteriaceae-specific clusters of orthologous genes) were identified in the 67 Bifidobacteriaceae (sub) species, of which 8359 had members present in at least two genomes. The pangenome size, when plotted versus the number of included genomes, clearly shows that the power trend line has yet to reach a plateau (Fig. 1). Actually, the number of new genes discovered by sequential addition of genome sequences was reduced from 839 to 636 BaeCOGs in the first three genomes additions to a number that ranged from 274 to 272 BaeCOGs in the final three additions, demonstrating the existence of an open pangenome within Bifidobacteriaceae family. This finding suggests that more members of the Bifidobacteriaceae family have yet to be identified, especially members of the family that do not belong to the Bifidobacterium genus, as these remain poorly characterized in various environments compared to the currently recognized bifidobacterial (sub)species.

Pan-genome analysis of the Bifidobacteriaceae family allowed the identification of 353 COGs shared by all 67 (sub) species, representing the core genome of currently sequenced Bifidobacteriaceae representatives (core BaeCOGs). An examination of the functional annotation of Core BaeCOGs employing the eggNOG database [45] shows that the most conserved core genes specify housekeeping functions such as replication, transcription and translation, or functions related to adaptation such as carbohydrate, nucleotide and amino acid metabolism as well as cell envelope biogenesis (Fig. 1).

The pan-genome analysis also allowed the identification of truly unique genes (TUGs) of the Bifidobacteriaceae family, i.e., those genes that are presented in one particular strain yet absent in any of the other examined representative of the Bifidobacteriaceae family. The number of TUGs range from 42 for $B$. indicum LMG 11587 to 585 for Bifidobacterium cuniculi LMG 10738. EggNOG analysis showed that the majority of TUGs (59\%) have no functional annotation (Additional file 1: Table S2). Nevertheless, taking into account the classified genes through the eggNOG analysis excluding the 


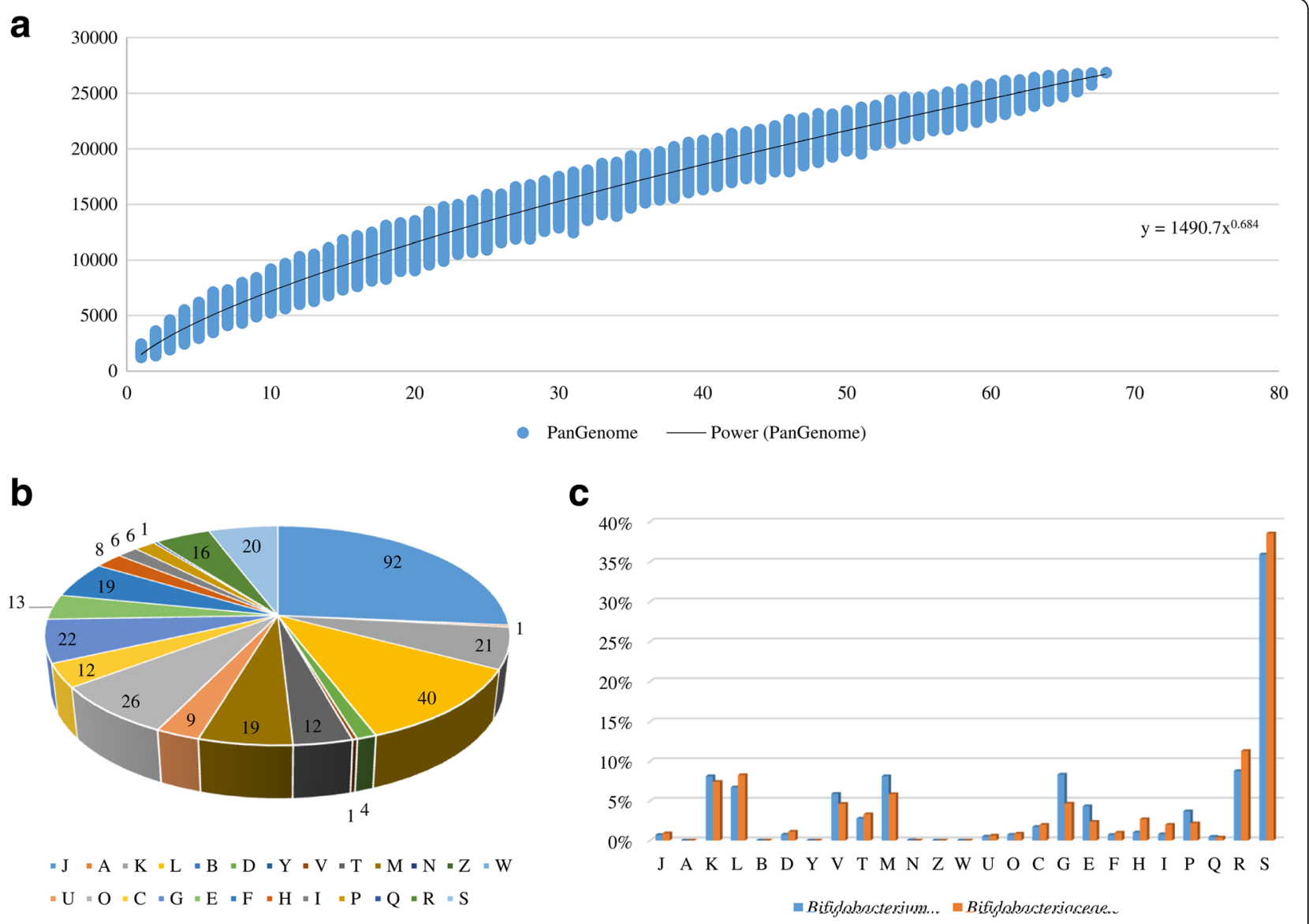

Fig. 1 Pan-genome and functional classification of genes of the Bifidobacteriaceae family. Panel a shows the pan-genome represented as variations of the sizes of the resulting gene pool upon sequential addition of the 67 Bifidobacteriaceae genomes. The $x$ axis represents the number of included genomes, whereas the $y$ axis represents the number of genes in the generated pan-genome. Panel $\mathbf{b}$ exhibits the number of core BaeCOGs associated with the predicted EggNOG classification. Panel $\mathbf{c}$ displays the percentages of TUGs associated with functional categories as classified through the EggNOG database between bifidobacterial and members of the Bifidobacteriaceae family that do not belong to the Bifidobacterium genus. COG families are identified by a one-letter abbreviation: A, RNA processing and modification; B, chromatin structure and dynamics; $C$, energy production and conversion; $\mathrm{D}$, cell cycle control and mitosis; $\mathrm{E}$, amino acid metabolism and transport; $\mathrm{F}$, nucleotide metabolism and transport; $\mathrm{G}$, carbohydrate metabolism and transport; $\mathrm{H}$, coenzyme metabolism; I, lipid metabolism; J, translation; K, transcription; L, replication and repair; M, cell wall/membrane/ envelope biogenesis; $\mathrm{N}$, cell motility; $\mathrm{O}$, post translational modification, protein turnover, and chaperone functions; $\mathrm{P}$, inorganic ion transport and metabolism; $Q$, secondary structure; $T$, signal transduction; $U$, intracellular trafficking and secretion; $Y$, nuclear structure; $V$, defense mechanisms; $Z$, cytoskeleton; R, general functional prediction only; S, function unknown

hypothetical and no-function genes, the highest number of genes fall in carbohydrate metabolism and cell envelope biogenesis together with replication and transcription. As mentioned above, these are the same four categories identified as containing the highest numbers of core BaeCOGs. Interestingly, the functional annotation of TUGs revealed that bifidobacterial genomes exhibit a higher abundance of TUGs involved in carbohydrate metabolism and cell envelope biogenesis compared to those of other members of the Bifidobacteriaceae family, reflecting a $38 \%$ and $78 \%$ of additional TUGs based on the average numbers between groups, respectively $[2,54]$ (Fig. 1 and Additional file 1: Table S2). These results are consistent with previous genomic and functional analyses based on the reference strains for each (sub) species of the Bifidobacterium genus indicating that bifidobacteria are under strong selective pressure to acquire and retain accessory genes for carbohydrate utilization in order to be competitive in the specific ecological niches in which they reside $[2,54]$.

\section{Phylogenomic analyses of members of the Bifidobacteriaceae family}

The availability of genome sequences for each member of the Bifidobacteriaceae family allowed an in-depth analysis of the evolutionary development followed by each member of this extensive family. A phylogenetic supertree was constructed based on the concatenation of 314 protein sequences that represent the core BaeCOGs with the exclusion of paralogs identified in each genome (Fig. 2). 


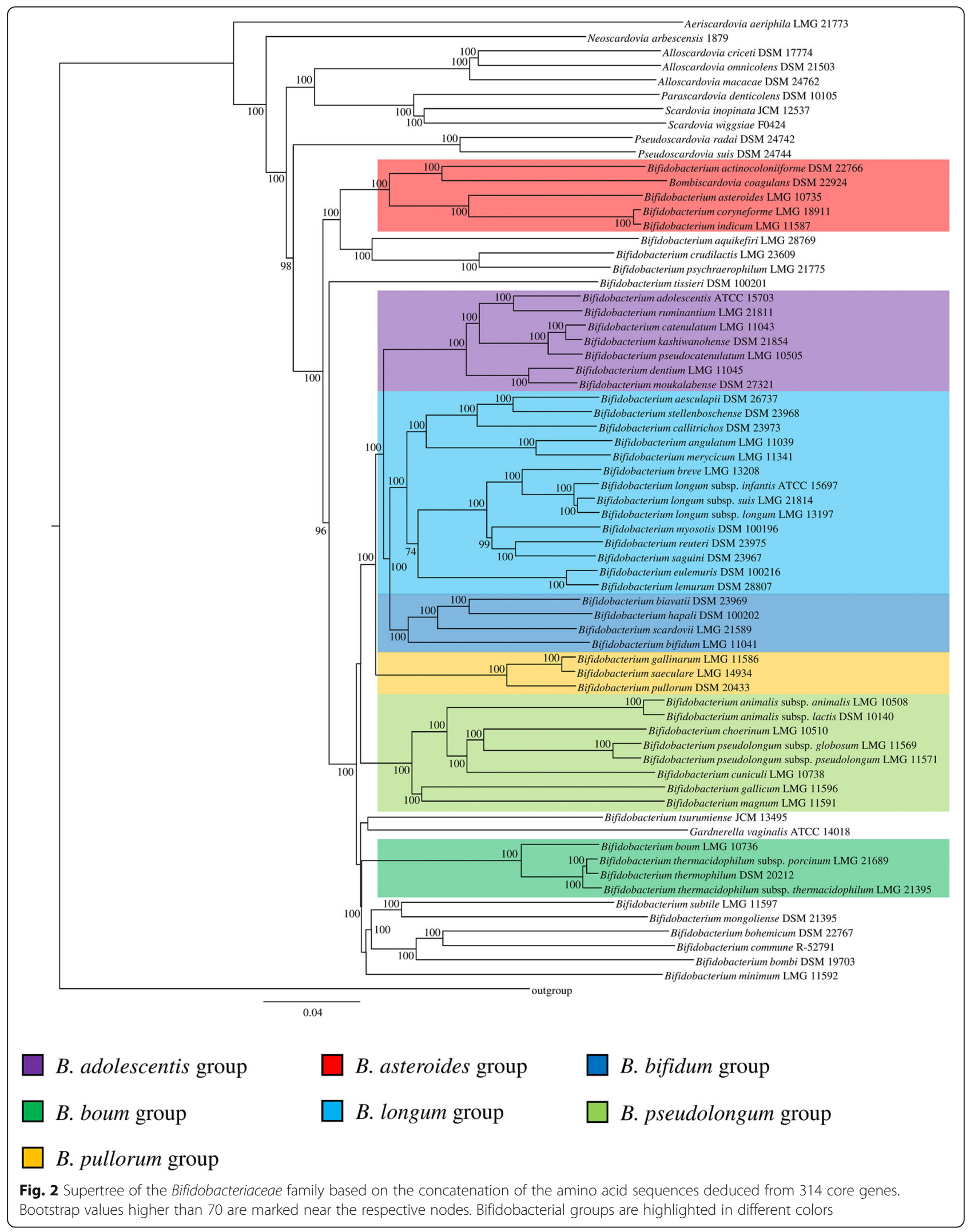


The generated phylogenetic supertree showed that ten strains of the Bifidobacteriaceae species that do not belong to the Bifidobacterium genus represent the deepest branches of this supertree, being separated from the 55 bifidobacterial (sub) species (Fig. 2). Consequently, the bifidobacterial species were positioned at the top of the supertree, reflecting their highest average gene ratio (1.24) as compared to the non-bifidobacterial members of the Bifidobacteriaceae family. Thus, these data clearly indicate that evolution of currently known bifidobacterial species involved a relatively limited number of ancestral gene loss incidences, yet an extensive number of gene acquisition events, corroborating previously published data [2]. Interestingly, two members of the Bifidobacteriaceae family that do not belong to the Bifidobacterium genus, i.e., G. vaginalis ATCC 14018 and Bo. coagulans DSM 22924, appear to possess a higher level of phylogenetic relatedness with bifidobacterial strains as compared to other, non-bifidobacterial members of the Bifidobacteriaceae family (Fig. 2). While G. vaginalis ATCC 14018 shares the same phylogenetic branch as that of Bifidobacterium subtile LMG 11597, Bo. coagulans DSM 22924 is positioned within the deepest branch of the Bifidobacterium genus, i.e., within the $B$. asteroides group [2, 10], exhibiting higher genome relatedness with Bifidobacterium actinocoloniiforme DSM 22766, which was also isolated from Bombus. In order to validate the branching of these two Bifidobacteriaceae strains, a phylogenetic tree based on the 16S rRNA genes was constructed, as well as a tree based on five housekeeping genes including hsp60, rpoB, $d n a \mathrm{~J}, d n a \mathrm{G}$ and $c l p \mathrm{C}$ (Additional file 2: Figure S1). While Bo. coagulans DSM 22924 shares the same phylogenetic branch with B. actinocoloniiforme DSM 22766 in both trees, G. vaginalis ATCC 14018 occupies different positions within these phylogenetic trees. Nonetheless, the housekeeping-based tree confirmed the position of $G$. vaginalis ATCC 14018 within the Bifidobacterium genus, while in the $16 \mathrm{~S}$ rRNA-based tree it is placed between bifidobacterial species and the other non-bifidobacterial species. These findings cast doubts on the correct taxonomical classification of Bo. coagulans DSM 22924, and reinforce the importance of a phylogenomic approach as a tool for taxonomic validation [55].

Furthermore, we investigated the occurrence of genes predicted to encode enzymes for anaerobic respiration in the pangenome of the members of the Bifidobacteriaceae as previously described for the genome of $B$. asteroides PRL2011 [10]. Such in silico analyses highlight the presence of a cytochrome $b d$ oxidase-encoding complex in the genome of Bo. coagulans DSM 22924 (Additional file 1: Table S3), including the $c y d \mathrm{~A}$ and $c y d \mathrm{~B}$, which code for structural subunit of the cytochrome, as well as $c y d C$ and $c y d \mathrm{D}$, encoding a transporter required for the cytochrome assembly [10]. Furthermore, these four genes were identified in 11 genomes of the Bifidobacteriaceae family, including six strains isolated from insects, i.e., B. actinocoloniiforme DSM 22766, Bifidobacterium bohemicum DSM 22767, Bifidobacterium bombi DSM 19703, Bifidobacterium commune R-52791, Bifidobacterium coryneforme LMG 18911 and B. indicum LMG 11587, highlighting a correlation between the presence of the cytochrome $b d$ oxidase complex and the ecological niche of isolation (Additional file 1: Table S3).

Based on the Bifidobacteriaceae supertree reconstruction, five out of the six bifidobacterial species that were newly sequenced as part of this study are positioned within one of the previously identified bifidobacterial groups $[24,56]$. Interestingly, four strains appear to belong to the Bifidobacterium longum group, i.e., B. myosotis DSM 100196, B. reuteri DSM 23975, B. eulemuris DSM 100216 and B. lemurum DSM 28807 (Fig. 2). This finding is in line with the particular ecological origin of these strains. In fact, each one of these four species was isolated from feces of monkeys, similar to the other two members that had previously been assigned to the $B$. longum group, i.e., Bifidobacterium stellenboschense DSM 23968 and Bifidobacterium callitrichos DSM 23973. These findings therefore highlight that the B. longum group includes bifidobacterial (sub) species isolated from humans and other related primates (Fig. 2). Furthermore, B. hapali DSM 100202 exhibits a genetic relatedness with Bifidobacterium biavatii DSM 23969, which belongs to the $B$. bifidum group [24]. Notably, B. tissieri DSM 100201 was shown to occupy a unique position within the Bifidobacteriaceae supertree. This observation was confirmed through an average nucleotide identity (ANI) analysis showing the highest value of $88.02 \%$ with the most related Alloscardovia criceti DSM 17774 strain. Notably, an ANI value below to $95 \%$ is assumed to be sufficient to classify that taxon as a distinct species [43]. B. tissieri DSM 100201 is therefore an interesting strain for further investigation due to its genetic divergence from other bifidobacterial taxa. In order to validate the species assignment for the other 10 sequenced members of the Bifidobacteriaceae family (Table 2) from a genomic prospective, the decoded genomes were subjected to ANI comparisons with the other 56 (sub) species that had been sequenced. The sequenced genomes of the 10 Bifidobacteriaceae strains showed ANI values below 95\%, confirming their status as distinct species, with a relatively high value of 93.8\% observed between B. eulemuris DSM 100216 and $B$. lemurum DSM 28807 (Additional file 1: Table S4).

Furthermore, the Bifidobacteriaceae supertree confirmed the phylogenetic relatedness of the recently decoded genome sequences of B. commune R-52791 and Bifidobacterium aesculapii DSM 26737, which occupy positions within the same branches with $B$. bohemicum DSM 22767 and $B$. stellenboschense DSM 23968, respectively [49, 57]. Such 
data further confirms the existence of a direct relatedness between the ecological origin of both strains, i.e., insects of the Bombus genus and monkeys of the Callitrichidae family.

\section{Enzymatic profiling and evolutionary development of the Bifidobacteriaceae family}

A functional profiling analysis was performed to assess the presence of genes encompassing carbohydrate, amino acid and fatty acid degradation pathways in each (sub) species of the Bifidobacteriaceae family. Normalizing the obtained number of gene matches with the overall genetic arsenal (i.e. total amount of genes) of each strain, non-bifidobacterial strains retrieved percentages that were slightly lower compared to the bifidobacterial strains, i.e., $7 \%, 11 \%$ and $9 \%$, respectively (Additional file 1: Table S5). Interestingly, all members of the Bifidobacteriaceae family possess the Bifidobacterium shunt pathway $[6,58]$, including the gene $x f p$ that encodes the enzyme D-xylulose 5-phosphate phosphoketolase/D-fructose 6-phosphate phosphoketolase, expanding the notion of this signature metabolic trait of bifidobacteria to the whole family.

To further investigate the carbohydrate utilization abilities encoded by the genomes of the 67 Bifidobacteriaceae (sub) species, an enzyme classification toward glycans was performed. This enzyme classification was based on the Carbohydrate Active Enzymes (CAZy) database [44], which encompasses all currently known genetic determinants involved in the breakdown and utilization of carbohydrates, and revealed that the pangenome of the Bifidobacteriaceae family includes 9742 genes predicted to encode carbohydrate-active enzymes, i.e., glycosyl hydrolases (GHs), glycosyl transferases (GTs), polysaccharide lyases (PLs), carbohydrate esterases (CEs) and carbohydrate binding modules (CBMs), present at $43.4 \%, 43.8 \%, 0.2 \% 5.9 \%$ and $12.6 \%$, respectively. This very substantial number of retrieved enzymes reflects the findings of a previous analysis conducted on the 47 type-strains of the Bifidobacterium genus, where the glycan-breakdown potential of bifidobacteria in the mammalian gut was subjected to an extensive scrutiny [54].

Focusing on GH identification, 3989 genes were predicted on the analyzed genomes of 55 bifidobacterial (sub) species, while the remaining 12 Bifidobacteriaceae genomes contain 573 such genes. The Bifidobacteriaceae genomes specify a large arsenal of $\mathrm{GH}$ families, were GH13, GH3, GH43, GH23, GH32 and GH25 outnumber the other identified families (Additional file 1: Table S6). Despite the higher average amount of predicted $\mathrm{GH}-$ encoding genes for a given bifidobacterial genome, i.e., 72, as compared to that for a non-bifidobacterial member of the Bifidobacteriaceae family, i.e., 48, normalization of $\mathrm{GH}$ counts against the total amount of predicted genes provided similar GH indexes, i.e., 0.039 and 0.032, respectively (Additional file 1: Table S6). Nonetheless, genomes of the 20 strains that exhibit the highest GH index all belong to the Bifidobacterium genus, and are nearly all isolated from fecal samples of humans and monkeys, chief among them being Bifidobacterium catenulatum LMG 11043, B. eulemuris DSM 100216, B. hapali DSM 100202 and B. biavatii DSM 23969 (Table 1). These results suggest that bifidobacteria that reside in the primate/human gut have enjoyed a relatively high number of adaptive events related to carbohydrate metabolism to benefit from a wider source of different nutrients present in this particular environment. In contrast, Bifidobacteriaceae species that exhibit a relatively low $\mathrm{GH}$ index originate from a broad spectrum of environments, such as the gut of insects or other animals, and sewage (Table 1). Furthermore, genomes with a low GH index correspond with the smaller genomic complement of certain members of the Bifidobacteriaceae family, probably due to gene decay characteristic of those microbes that are considered harmful for human health, such as G. vaginalis, A. omnicolens, S. inopinata and S. wiggsiae [59].

While gene acquisition events that occur during evolution of microbial genomes support adaptation to new ecological niches, gene loss on the other hand contributes to genome simplification in order to preserve energy and biological compounds $[59,60]$. Prediction of the complete Bifidobacteriaceae glycobiome content allowed us to estimate the acquisition and loss rates of genes encoding carbohydrate-active enzymes within this saccharolytic family. In order to depict gain and loss events of genes with a predicted function in carbohydrate metabolism, we collected the BaeCOGs that include GH-encoding genes obtained from the pan-genome analysis. The resulting 846 BaeCOGs were allocated among the Bifidobacteriaceae supertree showing that evolution of the current bifidobacterial (sub) species involved only a limited number of ancestral gene loss events, yet a substantial number of GHencoding gene acquisitions (Fig. 3). Thus, genes encoding GHs appear to have been acquired early in the evolution of bifidobacteria, followed by a simplification of the GHassociated gene arsenal that has resulted in or followed specialization toward those ecological niches in which current bifidobacterial species have been identified. Interestingly, members of the B. bifidum group possess the highest number of $\mathrm{GH}$-encoding gene acquisitions compared to those of other groups, probably in order to expand its metabolic ability towards different carbon sources present in the host, similar to what was mentioned above regarding GH index discrepancies (Fig. 3 and Table 1). Taking into account only those BaeCOGs that include members of GH families known to be involved in hostglycan degradation, i.e., GH20, GH29, GH33, GH38, GH95, GH101, GH112, GH125 and GH129 [54], the B. bifidum group, once again, displays the highest number of 


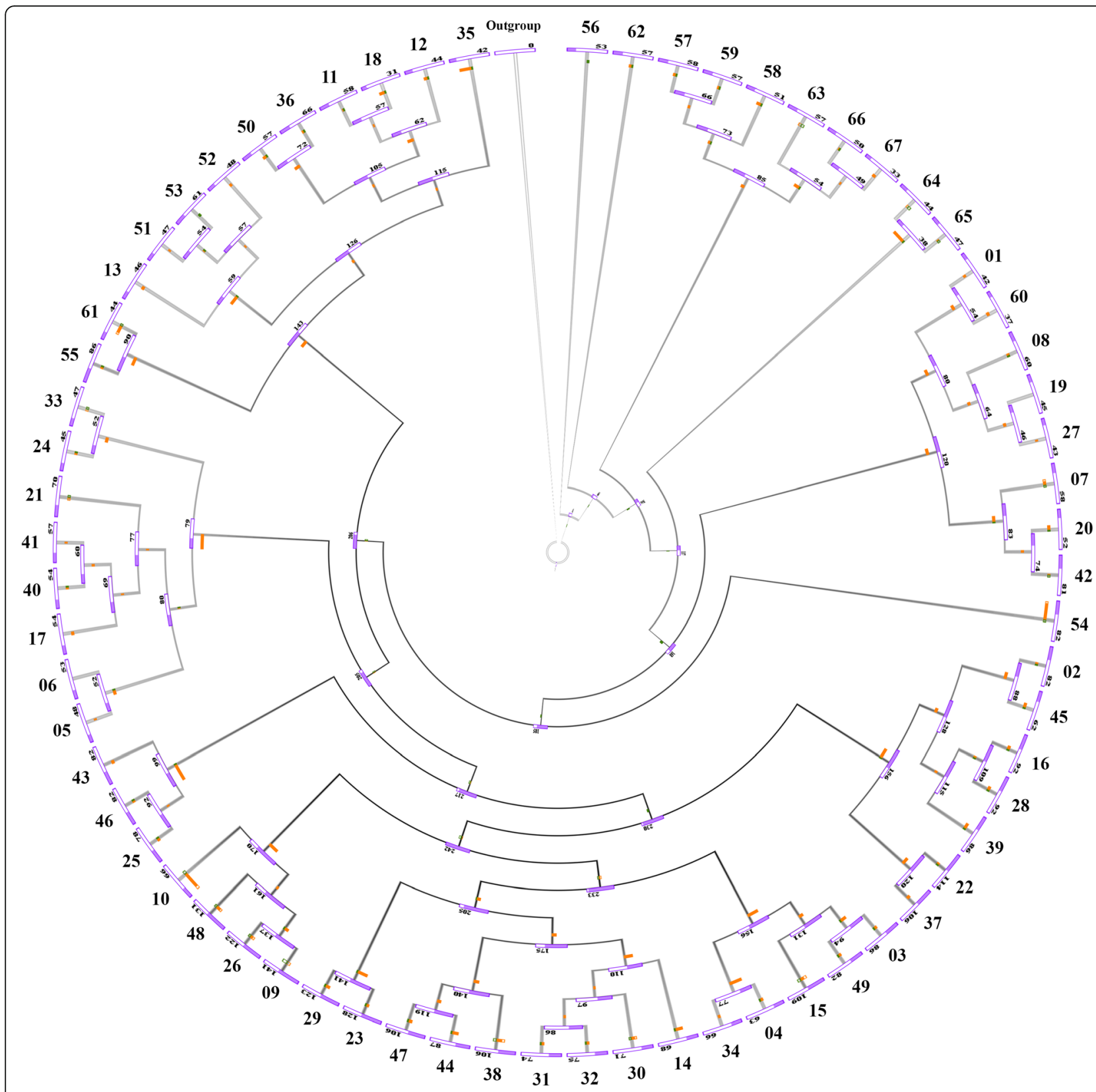

Fig. 3 Analysis of evolutionary gain and loss events as based on predicted GHs within the Bifidobacteriaceae family. The image displays the core gene-based supertree of the Bifidobacteriaceae family, where each node reports the number of predicted GHs identified for each strain. Furthermore, gain and loss events are indicated by green and orange bars on the edge leading to each node, while the numbers placed at the supertree leaves represent the related bifidobacterial taxa presented in Table 1

GH-encoding gene acquisitions (up to seven BaeCOGs). In this context $B$. bifidum exhibits the highest host-glycan degradation BaeCOGs acquisition number of the Bifidobacteriaceae family, thereby highlighting the capability of this bifidobacterial species to feed on host-glycan $[25,61,62]$.

\section{Conclusions}

A lot of effort has been invested in the dissection and characterization of the genomic content from different members of the Bifidobacterium genus [2, 11, 24-28]. In contrast, very little is known about the genomics of other members of the Bifidobacteriaceae family, which include apart from the Bifidobacterium genus eight additional genera. In this study, genome sequencing allowed us to explore the genome content of known members across the Bifidobacteriaceae family, as represented by 67 (sub) species, and to scrutinize the phylogenetic relatedness between each taxon belonging to this family. 
Bifidobacteria exhibit a higher number of genes per genome compared to other members of the Bifidobacteriaceae family, perhaps reflecting an increased competitiveness based on a broad spectrum of ecological niches from which they were isolated. The more complex genome content of bifidobacteria is also reflected by the capability of these microorganisms to degrade multiple carbon sources [54, 63]. Such findings were further validated in this study by the analyses of the pangenome of the members of the Bifidobacteriaceae family, which highlights the occurrence of a higher abundance of TUGs in bifidobacterial genomes dedicated to the carbohydrate metabolism and cell envelope biogenesis, when compared to such numbers for other members of the Bifidobacteriaceae family. Enzymatic gene profiling revealed that the 20 strains that showed the highest GH indexes belong to bifidobacterial strains that are nearly all isolated from humans or monkeys. Moreover, a gene gain/loss analysis shows that members of the Bifidobacterium genus isolated from such primates possess the highest number of $\mathrm{GH}$-encoding gene acquisitions, probably in order to expand their ability to metabolize different carbon sources. These results highlight a relatively large number of adaptive events related to carbohydrate metabolism among members of the Bifidobacterium genus that reside in omnivorous organisms that consume a wide variety of nutrients.

Furthermore, our phylogenomic analysis revealed possible taxonomic inconsistencies in the classification of $G$. vaginalis and Bo. coagulans, which displayed a close phylogenetic relatedness with other bifidobacterial strains, i.e., B. subtile LMG 11597 and B. actinocoloniiforme DSM 22766. Such findings further corroborate the strengths of genome-based analyses as an essential approach to be incorporated in phylogenome-based taxonomic studies.

\section{Additional files}

Additional file 1: Tables S1, S2, S3, S4, S5 and S6. (XLSX 3628 kb)

Additional file 2: Figure S1. Phylogenetic trees of the Bifidobacteriaceae family. Panel a display the $16 \mathrm{~S}$ rRNA gene-based tree of the current recognized (sub) species of the family. Panel b shows the phylogenetic tree based on the concatenation of the amino acid sequences of five housekeeping genes including hsp60, rpoB, dnaJ, dnaG and clpC. For each tree, bootstrap values higher than 70 are marked near the respective nodes. (TIFF 2260 kb)

\footnotetext{
Abbreviations

ANI: Average nucleotide identity; BaeCOGs: Bifidobacteriaceae-specific clusters of orthologous groups; CAZy: Carbohydrate active enzymes; CBMs: Carbohydrate binding modules; CEs: Carbohydrate esterases; GF: Gene family; GHs: Glycosyl hydrolases; GIT: Gastrointestinal tract; GTs: Glycosyl transferases; HMM: Hidden Markov Model; MRS: Man-Rogosa-Sharpe; NCBI: National Center for Biotechnology Information; ORFs: Open reading frames; PLs: Polysaccharide lyases; TUGs: Truly unique genes
}

\section{Acknowledgements}

Part of this research is conducted using the High Performance Computing (HPC) facility of the University of Parma.

\section{Funding}

This work was funded by the EU Joint Programming Initiative - A Healthy Diet for a Healthy Life (JPI HDHL, http://www.healthydietforhealthylife.eu/) to DvS (in conjunction with Science Foundaion Ireland [SFI], Grant number 15/JP-HDHL/3280) and to MV (in conjunction with MIUR, Italy). We thank GenProbio srl for financial support of the Laboratory of Probiogenomics. LM is supported by Fondazione Cariparma, Parma, Italy. DvS is a member of The APC Microbiome Institute funded by Science Foundation Ireland (SFI), through the Irish Government's National Development Plan (Grant number SFI/12/RC/2273). The authors declare that they have no competing interests.

\section{Availability of data and materials}

Genome sequences reported in this article have been deposited in GenBank under the following accession numbers: MWWQ00000000, MWWR00000000, MWWS00000000, MWWT00000000, MWWU00000000, MWWV00000000, MWWW00000000, MWWX00000000, MWWY00000000, MWWZ00000000 and MWXA00000000. The version described in this paper is version MWWQ01000000, MWWR01000000, MWWS01000000, MWWT01000000, MWWU01000000, MWWV01000000, MWWW01000000, MWWX01000000, MWWY01000000, MWWZ01000000 and MWXA01000000

\section{Authors' contributions}

GAL designed the study, performed analyses and wrote the manuscript. GAL, CM and LM performed bioinformatic analyses. SD, MMa, and CF performed genome sequencing of the bacterial strains. MMo, PM and KJ provided bacterial strains. DVS and FT participated and supervised the study. MV conceived the study, participated in its design and coordination, and contributed to the manuscript preparation. All authors read and approved the final manuscript

Ethics approval and consent to participate Not applicable.

\section{Consent for publication}

Not applicable.

\section{Competing interests}

The authors declare that they have no competing interests.

\section{Publisher's Note}

Springer Nature remains neutral with regard to jurisdictional claims in published maps and institutional affiliations.

\section{Author details \\ 'Laboratory of Probiogenomics, Department of Chemistry, Life Sciences and Environmental Sustainability, University of Parma, Parma, Italy. ${ }^{2}$ GenProbio srl, Parma, Italy. ${ }^{3}$ Department of Agricultural Sciences, University of Bologna, Bologna, Italy. ${ }^{4}$ Department of Microbiology, Nutrition and Dietetics, Faculty of Agrobiology, Food and Natural Resources, Czech University of Life

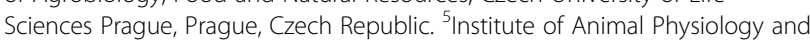 Genetics v.v.i., Academy of Sciences of the Czech Republic, Prague, Czech Republic. ${ }^{6} \mathrm{APC}$ Microbiome Institute and School of Microbiology, National University of Ireland, Cork, Ireland.}

Received: 7 April 2017 Accepted: 24 July 2017

Published online: 01 August 2017

References

1. Bergey DHGM, Whitman WB, Parte AC. The actinobacteria. Bergey's manual of systematic bacteriology. 2012;5:171-224.

2. Milani C, Lugli GA, Duranti S, Turroni F, Bottacini F, Mangifesta M, Sanchez B, Viappiani A, Mancabelli L, Taminiau B, et al. Genomic encyclopedia of type strains of the genus Bifidobacterium. Appl Environ Microbiol. 2014;80:6290-302.

3. Zhang G, Gao B, Adeolu M, Khadka B, Gupta RS. Phylogenomic analyses and comparative studies on genomes of the Bifidobacteriales: identification of molecular signatures specific for the order Bifidobacteriales and its different subclades. Front Microbiol. 2016;7:978. 
4. Strassert JF, Kohler T, Wienemann TH, Ikeda-Ohtsubo W, Faivre N, Franckenberg S, Plarre R, Radek R, Brune A. 'Candidatus Ancillula trichonymphae', a novel lineage of endosymbiotic Actinobacteria in termite gut flagellates of the genus Trichonympha. Environ Microbiol. 2012;14:3259-70.

5. Dworkin M, Falkow S, Rosenberg E, Schleifer K-H, Stackebrandt E. The prokaryotes. New York: Springer; 2006.

6. Ventura M, van Sinderen D, Fitzgerald GF, Zink R. Insights into the taxonomy, genetics and physiology of bifidobacteria. Antonie Van Leeuwenhoek. 2004:86:205-23.

7. Turroni F, Ventura M, Butto LF, Duranti S, O'Toole PW, Motherway MO, van Sinderen D. Molecular dialogue between the human gut microbiota and the host: a lactobacillus and Bifidobacterium perspective. Cell Mol Life Sci. 2014;71:183-203.

8. Mantzourani M, Fenlon M, Beighton D. Association between Bifidobacteriaceae and the clinical severity of root caries lesions. Oral Microbiol Immunol. 2009;24:32-7.

9. Catlin BW. Gardnerella vaginalis: characteristics, clinical considerations, and controversies. Clin Microbiol Rev. 1992;5:213-37.

10. Bottacini F, Milani C, Turroni F, Sanchez B, Foroni E, Duranti S, Serafini F, Viappiani A, Strati F, Ferrarini A, et al. Bifidobacterium asteroides PRL2011 genome analysis reveals clues for colonization of the insect gut. PLoS One. 2012;7:e44229.

11. Milani C, Duranti S, Lugli GA, Bottacini F, Strati F, Arioli S, Foroni E, Turroni F, van Sinderen D, Ventura M. Comparative genomics of Bifidobacterium animalis subsp. lactis reveals a strict monophyletic bifidobacterial taxon. Appl Environ Microbiol. 2013;79:4304-15.

12. Huys G, Vancanneyt M, D'Haene K, Falsen E, Wauters G, Vandamme P. Alloscardovia omnicolens gen. Nov., sp. nov., from human clinical samples. Int J Syst Evol Microbiol. 2007;57:1442-6.

13. Okamoto M, Benno Y, Leung KP, Maeda N. Metascardovia criceti gen. Nov Sp. Nov., from hamster dental plaque. Microbiol Immunol. 2007;51:747-54.

14. Simpson PJ, Ross RP, Fitzgerald GF, Stanton C. Bifidobacterium psychraerophilum sp. nov. and Aeriscardovia aeriphila gen. Nov., sp. nov., isolated from a porcine caecum. Int J Syst Evol Microbiol. 2004:54:401-6.

15. Leopold S. Heretofore undescribed organism isolated from the genitourinary system. U S Armed Forces Med J. 1953;4:263-6.

16. Piot $P$, van Dyck E, Goodfellow M, Falkow S. A taxonomic study of Gardnerella vaginalis (Haemophilus vaginalis) Gardner and Dukes 1955. J Gen Microbiol. 1980;119:373-96.

17. Piot P, Van Dyck E, Peeters M, Hale J, Totten PA, Holmes KK. Biotypes of Gardnerella vaginalis. J Clin Microbiol. 1984;20:677-9.

18. Yeoman CJ, Yildirim S, Thomas SM, Durkin AS, Torralba M, Sutton G, Buhay CJ, Ding Y, Dugan-Rocha SP, Muzny DM, et al. Comparative genomics of Gardnerella vaginalis strains reveals substantial differences in metabolic and virulence potential. PLoS One. 2010;5:e12411.

19. Forsum U, Hallen A, Larsson PG. Bacterial vaginosis-a laboratory and clinical diagnostics enigma. APMIS. 2005;113:153-61.

20. Jian W, Dong $X$. Transfer of Bifidobacterium inopinatum and Bifidobacterium denticolens to Scardovia inopinata gen. Nov., comb. nov., and Parascardovia denticolens gen. Nov., comb. nov., respectively. Int J Syst Evol Microbiol. 2002:52:809-12.

21. Modesto M, Biavati B, Mattarelli P. Occurrence of the family bifidobacteriaceae in human dental caries and plaque. Caries Res. 2006:40:271-6.

22. Beighton D, Gilbert SC, Clark D, Mantzourani M, Al-Haboubi M, Ali F, Ransome E, Hodson N, Fenlon M, Zoitopoulos L, Gallagher J. Isolation and identification of bifidobacteriaceae from human saliva. Appl Environ Microbiol. 2008;74:6457-60

23. Ventura M, Turroni F, Zomer A, Foroni E, Giubellini V, Bottacini F, Canchaya C, Claesson MJ, He F, Mantzourani M, et al. The Bifidobacterium dentium Bd1 genome sequence reflects its genetic adaptation to the human oral cavity. PLoS Genet. 2009;5:e1000785.

24. Lugli GA, Milani C, Turroni F, Duranti S, Ferrario C, Viappiani A, Mancabelli L, Mangifesta $M$, Taminiau B, Delcenserie $V$, et al. Investigation of the evolutionary development of the genus Bifidobacterium by comparative genomics. Appl Environ Microbiol. 2014;80:6383-94.

25. Duranti S, Milani C, Lugli GA, Turroni F, Mancabelli L, Sanchez B, Ferrario C, Viappiani A, Mangifesta M, Mancino W, et al. Insights from genomes of representatives of the human gut commensal Bifidobacterium bifidum. Environ Microbiol. 2015;17:2515-31.

26. Duranti S, Milani C, Lugli GA, Mancabelli L, Turroni F, Ferrario C, Mangifesta M, Viappiani A, Sanchez B, Margolles A, et al. Evaluation of genetic diversity among strains of the human gut commensal Bifidobacterium adolescentis. Sci Rep. 2016;6:23971.

27. Bottacini F, O'Connell Motherway M, Kuczynski J, O'Connell KJ, Serafini F, Duranti S, Milani C, Turroni F, Lugli GA, Zomer A, et al. Comparative genomics of the Bifidobacterium breve taxon. BMC Genomics. 2014;15:170.

28. O'Callaghan A, Bottacini F, O'Connell Motherway M, van Sinderen D. Pangenome analysis of Bifidobacterium longum and site-directed mutagenesis through by-pass of restriction-modification systems. BMC Genomics. 2015;16:832

29. Ventura M, Reniero R, Zink R. Specific identification and targeted characterization of Bifidobacterium lactis from different environmental isolates by a combined multiplex-PCR approach. Appl Environ Microbiol. 2001;67:2760-5.

30. JFSaDW R. Molecular cloning: a laboratory manual. Cold Spring Harbor Laboratory Press; 2001.

31. Lugli GA, Milani C, Mancabelli L, van Sinderen D, Ventura M. MEGAnnotator: a user-friendly pipeline for microbial genomes assembly and annotation. FEMS Microbiol Lett. 2016;363

32. Chevreux B, Pfisterer T, Drescher B, Driesel AJ, Muller WE, Wetter T, Suhai S. Using the miraEST assembler for reliable and automated mRNA transcript assembly and SNP detection in sequenced ESTs. Genome Res. 2004:14:1147-59.

33. Hyatt D, Chen GL, Locascio PF, Land ML, Larimer FW, Hauser LJ. Prodigal: prokaryotic gene recognition and translation initiation site identification. BMC Bioinformatics. 2010;11:119.

34. Lowe TM, Eddy SR. tRNAscan-SE: a program for improved detection of transfer RNA genes in genomic sequence. Nucleic Acids Res. 1997;25:955-64

35. Lagesen $\mathrm{K}$, Hallin P, Rodland EA, Staerfeldt HH, Rognes T, Ussery DW. RNAmmer: consistent and rapid annotation of ribosomal RNA genes. Nucleic Acids Res. 2007:35:3100-8.

36. Zhao $Y$, Tang H, Ye Y. RAPSearch2: a fast and memory-efficient protein similarity search tool for next-generation sequencing data. Bioinformatics. 2012;28:125-6.

37. Finn RD, Bateman A, Clements J, Coggill P, Eberhardt RY, Eddy SR, Heger A, Hetherington K, Holm L, Mistry J, et al. Pfam: the protein families database. Nucleic Acids Res. 2014;42:D222-30.

38. Rutherford K, Parkhill J, Crook J, Horsnell T, Rice P, Rajandream MA, Barrell B. Artemis: sequence visualization and annotation. Bioinformatics. 2000;16:944-5.

39. Zhao Y, Wu J, Yang J, Sun S, Xiao J, Yu J. PGAP: pan-genomes analysis pipeline. Bioinformatics. 2012;28:416-8.

40. Enright AJ, Van Dongen S, Ouzounis CA. An efficient algorithm for largescale detection of protein families. Nucleic Acids Res. 2002;30:1575-84.

41. Katoh K, Misawa K, Kuma K, Miyata T. MAFFT: a novel method for rapid multiple sequence alignment based on fast Fourier transform. Nucleic Acids Res. 2002;30:3059-66.

42. Larkin MA, Blackshields G, Brown NP, Chenna R, McGettigan PA, McWilliam H, Valentin F, Wallace IM, Wilm A, Lopez R, et al. Clustal W and Clustal X version 2.0. Bioinformatics. 2007;23:2947-8.

43. Richter M, Rossello-Mora R. Shifting the genomic gold standard for the prokaryotic species definition. Proc Natl Acad Sci U S A. 2009;106:19126-31.

44. Lombard V, Golaconda Ramulu H, Drula E, Coutinho PM, Henrissat B. The carbohydrate-active enzymes database (CAZy) in 2013. Nucleic Acids Res. 2014:42:D490-5

45. Huerta-Cepas J, Szklarczyk D, Forslund K, Cook H, Heller D, Walter MC, Rattei T, Mende DR, Sunagawa S, Kuhn M, et al. eggNOG 4.5: a hierarchical orthology framework with improved functional annotations for eukaryotic prokaryotic and viral sequences. Nucleic Acids Res. 2016;44:D286-93.

46. Caspi $R$, Altman $T$, Billington $R$, Dreher $K$, Foerster $H$, Fulcher CA, Holland TA, Keseler IM, Kothari A, Kubo A, et al. The MetaCyc database of metabolic pathways and enzymes and the BioCyc collection of pathway/genome databases. Nucleic Acids Res. 2014;42:D459-71.

47. Csuros M. Count: evolutionary analysis of phylogenetic profiles with parsimony and likelihood. Bioinformatics. 2010;26:1910-2.

48. Lugli GA, Duranti S, Milani C, Turroni F, Viappiani A, Mangifesta M, van Sinderen D, Ventura M. The genome sequence of Bifidobacterium moukalabense DSM 27321 highlights the close phylogenetic relatedness with the Bifidobacterium dentium taxon. Genome Announc. 2014;2.

49. Praet J, Meeus I, Cnockaert M, Aerts M, Smagghe G, Vandamme P. Bifidobacterium commune sp. nov. isolated from the bumble bee gut. Antonie Van Leeuwenhoek. 2015;107:1307-13.

50. Toh H, Yamazaki Y, Tashiro K, Kawarai S, Oshima K, Nakano A, Kim CN, Mimura I, Arakawa K, Iriki A, et al. Draft genome sequence of Bifidobacterium aesculapii DSM 26737T, isolated from feces of baby common marmoset. Genome Announc. 2015;3. 
51. Garcia-Aljaro C, Balleste E, Rossello-Mora R, Cifuentes A, Richter M, Blanch AR. Neoscardovia arbecensis gen. Nov., sp. nov., isolated from porcine slurries. Syst Appl Microbiol. 2012;35:374-9.

52. Sun Y, Tamarit D, Andersson SG. Switches in Genomic GC Content Drive Shifts of Optimal Codons under Sustained Selection on Synonymous Sites. Genome Biol Evol. 2016;

53. Chen L, Zheng D, Liu B, Yang J, Jin Q. VFDB 2016: Hierarchical and refined dataset for big data analysis-10 years on. Nucleic Acids Res. 2016;44:D694-7.

54. Milani C, Lugli GA, Duranti S, Turroni F, Mancabelli L, Ferrario C, Mangifesta M, Hevia A, Viappiani A, Scholz M, et al. Bifidobacteria exhibit social behavior through carbohydrate resource sharing in the gut. Sci Rep. 2015;5:15782

55. Chun J, Rainey FA. Integrating genomics into the taxonomy and systematics of the bacteria and archaea. Int J Syst Evol Microbiol. 2014;64:316-24.

56. Ventura M, Canchaya C, Del Casale A, Dellaglio F, Neviani E, Fitzgerald GF, van Sinderen D. Analysis of bifidobacterial evolution using a multilocus approach. Int J Syst Evol Microbiol. 2006;56:2783-92.

57. Modesto M, Michelini S, Stefanini I, Ferrara A, Tacconi S, Biavati B, Mattarell P. Bifidobacterium aesculapii sp. nov., from the faeces of the baby common marmoset (Callithrix Jacchus). Int J Syst Evol Microbiol. 2014;64:2819-27.

58. Scardovi V. LDT: The fructose-6-phosphate shunt as a peculiar pattern of hexos degradation in the genus Bifidobacterium. Annali di Microbiologia ed Enzimologia. 1965:15:19-23.

59. Albalat R, Canestro C. Evolution by gene loss. Nat Rev Genet. 2016;17:379-91.

60. Mira A, Ochman H, Moran NA. Deletional bias and the evolution of bacteria genomes. Trends Genet. 2001;17:589-96.

61. Turroni F, Bottacini F, Foroni E, Mulder I, Kim JH, Zomer A, Sanchez B, Bidossi A, Ferrarini A, Giubellini V, et al. Genome analysis of Bifidobacterium bifidum PRL2010 reveals metabolic pathways for host-derived glycan foraging. Proc Natl Acad Sci U S A. 2010;107:19514-9.

62. Turroni F, Milani C, van Sinderen D, Ventura M. Genetic strategies for mucin metabolism in Bifidobacterium bifidum PRL2010: an example of possible human-microbe co-evolution. Gut Microbes. 2011;2:183-9.

63. Pokusaeva K, Fitzgerald GF, van Sinderen D. Carbohydrate metabolism in Bifidobacteria. Genes Nutr. 2011;6:285-306.

\section{Submit your next manuscript to BioMed Central and we will help you at every step:}

- We accept pre-submission inquiries

- Our selector tool helps you to find the most relevant journal

- We provide round the clock customer support

- Convenient online submission

- Thorough peer review

- Inclusion in PubMed and all major indexing services

- Maximum visibility for your research

Submit your manuscript at www.biomedcentral.com/submit

) Biomed Central 